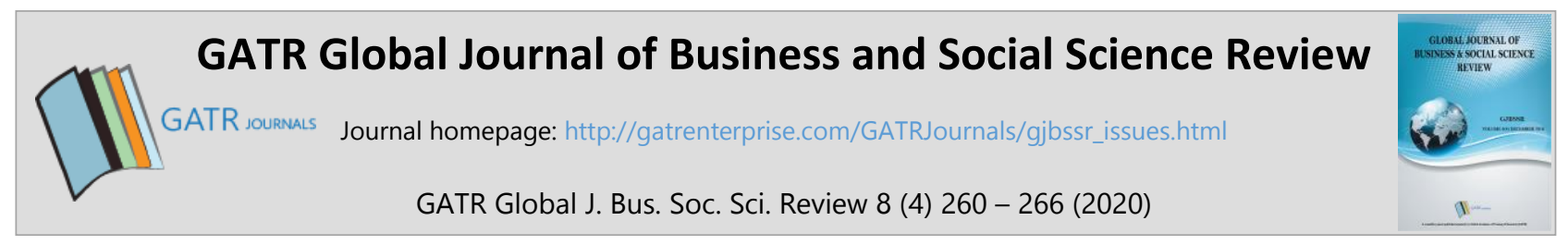

\title{
Better Park Design Contributes to Physical Activity Improvement
}

\author{
Sigit Arifwidodo*1, Orana Chandrasiri ${ }^{2}$ \\ ${ }^{1}$ Department of Landscape Architecture, Faculty of Architecture, Kasetsart University, 50 Ngamwongwan Rd, Bangkok \\ 10900, Thailand \\ ${ }^{2}$ International Health Policy Program, Ministry of Public Health, 88/20 Satharanasuk 6 Alley, Nonthaburi 11000, \\ Thailand
}

\begin{abstract}
Objective - Empirical evidence has identified that parks hold an essential role in promoting physical activity. Parks facilitate opportunities to be physically active for a wide range of users. The paper explores the effects of design intervention of Benjakitti Park, a public park in Bangkok, Thailand.

Methodology/Technique - The system for Observing Play and Recreation in Communities (SOPARC) method was utilized before and after design intervention to understand whether the design intervention improved the park users' physical activity level. A survey questionnaire of park visitors was used to understand whether they had become more active during a park visit.

Finding -It was found that the design intervention changed the characteristics of park users and their activity patterns. More children and older adults' visitors were observed in the post-design intervention. An ordinary least square model of the survey questionnaire result showed that one-time park visitation was associated with an increase of five minutes of moderate and vigorous physical activity per week. The study showed that even a small design intervention could change people's behavior towards a healthier and more active lifestyle.
\end{abstract}

Type of Paper: Empirical

JEL Classification: C99, R19

Keywords: Public Park; Physical Activity; Landscape Design; Public Health; SOPARC.

Reference to this paper should be made as follows: Arifwidodo, S; Chandrasiri, O. (2020). Better Park Design Contributes to Physical Activity Improvement, GATR Global J. Bus. Soc. Sci. Review, 8(4): 260 - 266. https://doi.org/10.35609/gjbssr.2020.8.4(7)

\section{Introduction}

A recent development in literature on the built environment and physical activity has focused on designing parks to facilitate physical activity in communities better. It is now becoming a standard recommendation in cities that parks must be planned and designed to have physical activity benefits. Previous studies have suggested that important built environment factors such as neighborhood characteristics and proximity to parks are important in encouraging physical activity among different age, socioeconomic, and ethnocultural groups. (Bedimo-Rung et al., 2005).

\footnotetext{
${ }^{*}$ Paper Info: Revised: November 15, 2020

Accepted: December 31, 2020

* Corresponding author: Sigit Arifwidodo

E-mail: sigit.d@ku.ac.th

Affiliation: Department of Landscape Architecture, Faculty of Architecture, Kasetsart University, Thailand
} 
Despite the growing body of literature on parks and physical activity, evidence on active living and recreational physical activity in Asian cities are still rare in Thailand (Arifwidodo, 2005). Different climate and seasonality may reveal different patterns and characteristics of park use. Weather can affect how a park is used daily and change the patterns of activity in different seasons. For example, many studies on park use in the US have found that the number of users and activities were similar during the morning, afternoon, and evening observation periods (Cohen et al., 2015). On the other hand, studies in Thailand and Singapore have found that most users visited the parks during the morning and evening due to hot and humid weather in the afternoon (Arifwidodo, 2020). Types of the user were also different between eastern and western context. For example, studies in the US and European cities found that children and adolescents were the most dominant groups. Studies in the eastern part of the world revealed that most park users were adult and older adult groups (Arifwidodo and Chandrasiri, 2020).

In Thailand, the built environment is not designed conducive to physical activity. Microclimate and air pollution also discourage people from engaging in physical activity in public spaces. On the other hand, the existing infrastructure for physical activity provided by the Bangkok Metropolitan Administration could not fully support physical activity promotion (Chandrasiri, 2015). In addition to this, parks and green spaces were considered secondary in Thailand's infrastructure planning, where roads and highways were seen as more critical in boosting economic development (Arifwidodo, 2014; Limthongsakul et al., 2017). The lack of attention in park planning and design resulted in negative externalities, such as inappropriate use and vandalism.

The present study is designed to explore the changes in users' characteristics and patterns of activities in the public park after it was renovated. Suppose public health and urban planning sectors were to invest in creating an active environment conducive to physical activity. In that case, there is a need to understand that better park design can affect changes in human behaviors.

\section{Research Methodology}

The study is an intervention assessment of public parks for physical activity promotion. It examines the effects of the design intervention in a public park and assesses whether the park users' intervention physical activity. Hence, it requires two datasets: before the intervention or "pre-intervention" and after the intervention, or "post-intervention." Both datasets were then compared to explore the changes in users' characteristics and activity patterns.

The study selected was Benjakitti Park, one of the largest public parks in Bangkok, Thailand. The park was chosen for three reasons: (1) it was located in the middle of the commercial district in downtown Bangkok, which made the park had more diverse kind of users and activities, (2) it had one of the highest number of visitors among public parks in Bangkok, (3) it received a small renovation as a pilot project for an active park in Thailand and a showcase for the past ISPAH 2016 Conference.

We employed the System for Observing Play and Recreation in Communities (SOPARC) method to obtain park use and park user characteristics. System for Observing Play and Recreation in Communities (SOPARC) is a validated direct observation tool for assessing park and recreation areas, including park users' physical activity levels, gender, activity modes/types, and estimated age ethnicity groupings (McKenzie and Cohen, 2006). SOPARC was designed to obtain observational data on the number of participants and their physical activity levels during physical activity and leisure opportunities in community environments. It also provides contextual information on the setting in which physical activity occurs (McKenzie, 2010). It also collects information on park activity area characteristics (e.g., accessibility, usability, supervision, and organization). SOPARC observation in Benchakitti was adjusted from the original version in terms of the unit of analysis. The observation recorded individual users as one unit of analysis.

We conducted a pre-intervention survey to understand the park's existing activities and a post-intervention survey to understand whether the design intervention has changed the activity patterns. Then we coded all activities that occurred in the park into numbers and grouped them into three different levels of physical

GATR Global J. Bus. Soc. Sci. Review 8 (4) 260 -266 (2020) 
activity based on Metabolic Equivalent of Task (MET): sedentary behavior, light physical activity, and medium and vigorous physical activity. The objective is to compare the pre-and post-design intervention and understand whether the design has achieved the objective of increasing the number of specific users. As Chandrasiri and Arifwidodo (2017) pointed out, the objective of redesigning the park was to increase the number of children and elderly as well as to increase the number of light physical activity.

The pre-intervention survey was conducted for four days from 6-9 August 2015, while a post-intervention survey was conducted 9-12 April 2017. The questionnaire for post-intervention was conducted on 9-22 April 2017. Analysis of SOPARC data includes two datasets: the data from before and after the intervention using descriptive and inferential statistics. A descriptive comparison between the individual data from two periods was compared and examined. We also analyzed aggregated data (per observation measure) by transforming individual data from both pre and post design intervention. The data then analyzed using an independent $\mathrm{t}$ test to understand the association between design interventions and the change of patterns in physical activity. Analysis of questionnaire data involves the data from pre and post-intervention using descriptive and multivariate statistical analysis to understand the perception and preference of users towards design intervention in the park and physical activity in general. Satisfaction towards aspects of Active Park was compared to understand the changes in the patterns.

\section{Results and Discussion}

During the post-intervention SOPARC observation, a total of 12,506 users were recorded. This number shows a $10 \%$ increase from pre-intervention (11,329 users). Table 1 summarizes the SOPARC result comparison between pre and post design intervention.

Table 1. Pre and Post Intervention Comparison of Park User

\begin{tabular}{|c|c|c|c|c|c|}
\hline Criteria & $\begin{array}{c}\text { Pre-Design } \\
\text { Intervention } \\
(\%)\end{array}$ & $\begin{array}{c}\text { Post Design } \\
\text { Intervention }(\%)\end{array}$ & $\begin{array}{c}\text { Changes in } \\
\text { percentage }(\%)\end{array}$ & $\begin{array}{l}\text { P-value } \\
\text { (2-tailed) }\end{array}$ & $\begin{array}{c}\text { Mean } \\
\text { difference }\end{array}$ \\
\hline \multicolumn{6}{|c|}{ Zone } \\
\hline 1 road side & $3758(33.2)$ & $5117(40.9)$ & $36.2 \%$ & n.a & n.a \\
\hline 2 right side & $4641(41.0)$ & $4432(35.4)$ & $-4.5 \%$ & n.a & n.a \\
\hline 3 park/play & $2098(18.5)$ & 2364 (18.9) & $1.2 \%$ & n.a & n.a \\
\hline 4 river/bike & $832(7.3)$ & $593(4.7)$ & $28.7 \%$ & n.a & n.a \\
\hline \multicolumn{6}{|c|}{ Nationality } \\
\hline Thai & $10222(90.2)$ & $10579(84.6)$ & $3.4 \%$ & 0.870 & 67.69 \\
\hline Non-Thai & $1107(9.8)$ & $1925(15.4)$ & $73.8 \%$ & $0.001 *$ & 7.46 \\
\hline \multicolumn{6}{|c|}{ Gender } \\
\hline Male & $6635(58.6)$ & $7116(56.9)$ & $7.2 \%$ & 0.688 & 37.23 \\
\hline Female & $4694(41.4)$ & $5390(43.1)$ & $14.8 \%$ & 0.549 & 36.11 \\
\hline \multicolumn{6}{|c|}{ Age group } \\
\hline Children & $440(3.9)$ & $532(4.3)$ & $20.9 \%$ & 0.004* & 2.875 \\
\hline Teen & $1235(10.9)$ & $745(6.0)$ & $39.6 \%$ & $0.048 *$ & 14.40 \\
\hline Adult & $8065(71.2)$ & $9093(72.7)$ & $12.7 \%$ & 0.582 & 31.96 \\
\hline Elderly & $1589(14.0)$ & $2136(17.1)$ & $34.4 \%$ & $0.046^{*}$ & 18.03 \\
\hline \multicolumn{6}{|c|}{ PA level } \\
\hline Sedentary & $1179(10.4)$ & $1759(14.1)$ & $49.1 \%$ & $0.012 *$ & 18.12 \\
\hline Light PA & $4802(42.4)$ & $5429(43.4)$ & $13.0 \%$ & $0.015^{*}$ & 19.59 \\
\hline MVPA & $5348(47.2)$ & $5318(42.5)$ & $-0.5 \%$ & 0.979 & 0.94 \\
\hline TOTAL & $11329(100)$ & $12506(100)$ & $10.0 \%$ & & \\
\hline
\end{tabular}


The data shows that there is a significant increase in sedentary and light PA. The changes are functional because the design is considered a success since the objective was to reduce conflict between users exceptionally sedentary/light and moderate-vigorous physical activity. Before the intervention, the sedentary/light group was marginalized in the park. Slow runners and walkers got scolded by fast runners in jogging tracks, slow bikers got scolded by fast bikers, and fast bikers hit other users, mostly the elderly and children. So we did a design intervention to improve safety for the sedentary/light group.

Moreover, the data shows that it was a success. The result shows that there is a significant difference in mean in children, teens, and the elderly group. It means that design intervention is significantly associated with the age groups of users. It is probably because of the changes in the PA levels. The increase of sedentary and light PA in the park mostly are associated with the increase of children, teens, and elderly users. This change is a good sign because the design intervention also involves renovating the playground, which is specially designed for children. The main problem with this park is the lack of children in the park due to safety reasons, mainly from bike users who ride too fast. We recorded five accidents related to bike users that hit children and the elderly during the pre-intervention survey, and we did not find similar accidents during the post-intervention survey.

Table 2. Comparison of the total number of users stratified by activity

\begin{tabular}{|c|c|c|c|}
\hline Activity & Pre-Intervention (\%) & Post-Intervention (\%) & \% of changes \\
\hline Sitting/laying down & $1272(11.2)$ & $1235(9.9)$ & -2.9 \\
\hline Chatting & $195(1.7)$ & $119(1.0)$ & -39.0 \\
\hline Reading & $24(0.2)$ & $98(0.8)$ & 308.3 \\
\hline Picnic (with food) & $16(0.1)$ & $82(0.7)$ & 312.5 \\
\hline Other sedentary & $169(1.5)$ & $225(1.8)$ & 8.9 \\
\hline Walking & $4190(37.0)$ & $4561(36.5)$ & 49.0 \\
\hline Yoga, tai chi & $255(2.3)$ & $380(3.0)$ & -24.2 \\
\hline Using exercise & $488(4.3)$ & $370(3.0)$ & 781.8 \\
\hline equipment & & & -73.8 \\
\hline Skateboard & $11(0.1)$ & $97(0.8)$ & 4.1 \\
\hline Other LPA & $80(0.7)$ & $21(0.2)$ & 17.6 \\
\hline Bicycling & $778(6.9)$ & $810(6.5)$ & 42.2 \\
\hline Running & $3751(33.1)$ & $4412(35.3)$ & 200 \\
\hline Boating & $64(0.6)$ & $91(0.7)$ & -94.3 \\
\hline Rowing & $1(0.0)$ & $3(0.0)$ & $2(0.0)$ \\
\hline Other MVPA & $35(0.3)$ & & \\
\hline
\end{tabular}

Table 2 summarizes the changes in activity structure in the park. It can be seen that there is a $4.1 \%$ increase in biking and a $17.6 \%$ increase in running activities in the park. However, this increase is considered small since it does not improve the total moderate-vigorous physical activity level in the park.

We also conducted the pre and post questionnaire for the park users. The objective is to understand the changes in the perception of how they use the park and their behavior towards physical activity in the park. For analysis concerning design intervention, we collected the same number of respondents, 204. Table 3 summarizes the characteristics of users post-intervention.

Table 3 User characteristics from the post-intervention questionnaire

\begin{tabular}{|c|c|c|c|c|c|c|}
\hline Variables & Mean & Median & Mode & Std. Dev & Min & Max \\
\hline Gender* & 1.54 & 2 & 2 & 0.499 & 1 & 2 \\
\hline Age & 35.89 & 33 & 32 & 15.45 & 12 & 88 \\
\hline Marital status & 1.46 & 1 & 1 & 0.68 & 1 & 4 \\
\hline
\end{tabular}




\begin{tabular}{|c|c|c|c|c|c|c|}
\hline Education & 3.7 & 4 & 4 & 0.82 & 1 & 5 \\
\hline Household Status & 2.2 & 3 & 3 & 0.94 & 1 & 4 \\
\hline Average income & 29,096 & 15,000 & 0.00 & 48,551 & 0 & 450,000 \\
\hline Current weight & 62.8799 & 62 & 55 & 13.2 & 40 & 113 \\
\hline Height & 165.23 & 165 & 160 & 8.59 & 145 & 188 \\
\hline Smoking addiction* & 1.95 & 2 & 2 & 0.21 & 1 & 2 \\
\hline Regular alcohol drinker* & 1.91 & 2 & 2 & 0.29 & 1 & 2 \\
\hline Chronic disease* & 1.23 & 1 & 1 & 0.57 & 1 & 2 \\
\hline
\end{tabular}

Note: $*$ binary variable, for gender variable, $1=$ male, $2=$ female. On Smoking addiction, regular alcohol drinker, and chronic disease, 1 = yes, $2=$ no.

The average age of users is 35.89 years old, with $46.1 \%$ are male respondents. Most respondents do not have health risk behavior such as smoking addiction (only 4.9\%), regular alcohol consumption (9.3\%), and chronic diseases (non-NCD 7.4\%, NCD 7.8\%). It can be said that most of the respondents are engaged in physical activity (59.3\% of respondents participated in running/jogging). Table 5 summarizes some issues explored during the analysis.

Table 4 shows that there is a change of characteristics of users in the park. First, before the intervention, the park was associated with middle-class income users, which eventually marginalized low-income users, especially communities located near the park (for the pre-intervention analysis, please refer to a study conducted by Chandrasiri and Arifwidodo, 2017). However, after the intervention, it seems that there is no association between average income and the frequency of use of the park. It means that the increasing number of users based on SOPARC analysis mostly comes from the communities near the park. This argument is strengthened by the fact that there is a statistically significant association between distance from home and the frequency of use. On the other side, the association between distance from office and frequency of use is not statistically significant. It also provides evidence that the park users are now more mix between people who work near the park and people whose home is near the park.

Table 4. Spearman Rho correlation for questionnaire variables

\begin{tabular}{|c|c|c|}
\hline Variables & Coefficient & P-value \\
\hline Frequency of use - recreation PA & 0.311 & $0.001^{* * *}$ \\
\hline Average income - frequency of use & -0.023 & 0.747 \\
\hline Distance from home - frequency of use & 0.679 & $0.000^{* * *}$ \\
\hline Distance from office - frequency of use & 0.571 & 0.340 \\
\hline Park visitation - leisure-time physical activity & 0.779 & $0.000^{* * *}$ \\
\hline
\end{tabular}

Note: $* * *=\mathrm{p}<0.001$

We create a cross-tabulation between the frequency of park visits and the number of minutes of leisuretime physical activity. We found a statistically significant association, meaning that the higher the frequency of park visits, the higher the leisure-time physical activity. We also created an OLS regression model to understand the relationship between park visitation and physical activity outcomes. Table 5 summarizes the result. 
Table 5. OLS regression model of park visitation and physical activity outcomes

\begin{tabular}{|c|c|c|c|c|}
\hline \multirow{2}{*}{ Variable } & \multicolumn{2}{|c|}{ Unadjusted } & \multicolumn{2}{c|}{ Adjusted } \\
\cline { 2 - 5 } & Std. beta & P-value & Std. beta & P-value \\
\hline $\begin{array}{c}\text { Work-related physical activity (model } \\
\text { 1) }\end{array}$ & 0.093 & 0.176 & 0.057 & 0.366 \\
\hline $\begin{array}{c}\text { Transportation physical activity } \\
\text { (model 2) }\end{array}$ & 0.064 & 0.349 & 0.072 & 0.251 \\
\hline $\begin{array}{c}\text { Leisure-time physical activity (model } \\
\text { 3) }\end{array}$ & 0.298 & $0.000^{*}$ & 0.224 & $0.000^{*}$ \\
\hline
\end{tabular}

Note: Dependent variable for model 1 is the number of minutes of work-related physical activity in the last month, model 2 is the number of minutes of transportation-related physical activity in the last month, model 3 is the number of minutes of leisure-related physical activity in the last month. Model adjusted with gender, age, marital status, education, household status, average income, height, weight, smoking addiction, regular alcohol drinker, chronic disease, and frequency of Visiting Park.

Table 5 shows that park visitation is significantly associated with leisure-time physical activity in both models. We can infer two things from this finding. First, People come to Benchakitti Park to engage in physical activity. The higher the frequency, the higher the number of minutes spent per week of physical activity. One park visit per week will increase by 5 minutes in leisure-time of physical activity per week based on the model. Second, the park is suitable as a place to promote physical activity. The park has the image of an active park, has appropriate facilities and amenities, and has a high volume of users engaging in physical activity. The fact that work-related PA and transportation PA is not significant maybe has more relations with the user's lifestyle. It should alert us that physical activity promotion should happen not only in the park but also in other domains where it matters.

\section{Conclusion}

The paper explores the post-intervention evaluation of public park renovation. Using a case study of the Benjakitti Park in Bangkok, Thailand, we found that the design intervention changed the park's characteristics and activity patterns. There was an increasing number of children and elderly groups (21\% and $34 \%$ ). There was also an increased number of visitors conducting the physical activity. An OLS regression model found that one park visit can contribute to a five-minute increase of medium and vigorous physical activity in a week. The case study in Benjakitti Park shows that the design intervention of improving the physical condition in the park has been successful in increasing the number of users in the park and has achieved the design objectives. Furthermore, the design intervention provides us a more precise picture of the critical role of Public Park in physical activity promotion.

\section{References}

Arifwidodo, S. D. (2014). Urban form and residential energy use in Bandung Indonesia. In Urbanization in Asia (pp. 239-248). Springer, New Delhi. https://doi.org/10.1007/978-81-322-1638-4_14

Arifwidodo, S. D. (2015). Factors contributing to urban heat Island in Bangkok, Thailand. ARPN Journal of Engineering and Applied Sciences, 10(15), 6435-6439.

Arifwidodo, S. D., \& Chandrasiri, O. (2013). The relationship between housing tenure, sense of place and environmental management practices: A case study of two private land rental communities in Bangkok, Thailand. Sustainable Cities and Society, 8, 16-23. https://doi.org/10.1016/j.scs.2012.11.003

Arifwidodo, S. D., \& Chandrasiri, O. (2020). Association Between Park Characteristics and Park-Based Physical Activity Using Systematic Observation: Insights from Bangkok, Thailand. Sustainability, $12(6), 2559$. https://doi.org/10.3390/su12062559 
Bedimo-Rung, A. L., Mowen, A. J., \& Cohen, D. A. (2005). The significance of parks to physical activity and public health: a conceptual model. American journal of preventive medicine, 28(2), 159-168.

Chandrasiri, O., \& Arifwidodo, S. (2017). Inequality in active public park: a case study of Benjakitti Park in Bangkok, Thailand. Procedia engineering, 198, 193-199. https://doi.org/10.1016/j.proeng.2017.07.083

Chandrasiri, O. (Ed.) (2015). The Role of Public Parks in Promoting Physical Activity [in Thai], Kasetsart University, Bangkok.

Cohen, D. A., Han, B., Isacoff, J., Shulaker, B., Williamson, S., Marsh, T., ... \& Bhatia, R. (2015). Impact of park renovations on park use and park-based physical activity. Journal of physical activity and health, 12(2), 289-295. https://doi.org/10.1123/jpah.2013-0165

Department of Physical Activity Public Health. (2013). Department of Physical Activity and Public Health Newsletter year 2 Volume 4 [in Thai]. Department of Health, Nonthaburi.

Gobster, P. H. (1995). Perception and use of a metropolitan greenway system for recreation. Landscape and Urban Planning, 33(1-3), 401-413. https://doi.org/10.1016/0169-2046(94)02031-A

Limthongsakul, S., Nitivattananon, V., \& Arifwidodo, S. D. (2017). Localized flooding and autonomous adaptation in peri-urban Bangkok. Environment and Urbanization, 29(1), 51-68. https://doi.org/10.1177/0956247816683854

McCormack, G. R., Rock, M., Toohey, A. M., \& Hignell, D. (2010). Characteristics of urban parks associated with park use and physical activity: A review of qualitative research. Health \& place, 16(4), 712-726. https://doi.org/10.1016/j.healthplace.2010.03.003

Chandrasiri, O., \& Arifwidodo, S. (2017). Inequality in active public park: a case study of Benjakitti Park in Bangkok, Thailand. Procedia engineering, 198, 193-199.

McKenzie, T. L. (2010). 2009 CH McCloy lecture seeing is believing: observing physical activity and its contexts. Research quarterly for exercise and sport, 81(2), 113-122.

National Statistical Office, Survey on Population Behaviour in Playing Sport or Physical Exercise and Mental Health 2011 [in Thai]. First ed., National Statistical Office, Bangkok, 2012.

Pikora, T., Giles-Corti, B., Bull, F., Jamrozik, K., \& Donovan, R. (2003). Developing a framework for assessment of the environmental determinants of walking and cycling. Social science \& medicine, 56(8), 1693-1703. https://doi.org/10.1016/S0277-9536(02)00163-6

Ramirez, L. K. B., Hoehner, C. M., Brownson, R. C., Cook, R., Orleans, C. T., Hollander, M., ... \& Petersmarck, K. (2006). Indicators of activity-friendly communities: an evidence-based consensus process. American journal of preventive medicine, 31(6), 515-524. https://doi.org/10.1016/j.amepre.2006.07.026

Reynolds, K. D., Wolch, J., Byrne, J., Chou, C. P., Feng, G., Weaver, S., \& Jerrett, M. (2007). Trail characteristics as correlates of urban trail use. American Journal of Health Promotion, 21(4_suppl), 335-345. doi/abs/10.4278/0890-117121.4s.335

Sallis, J.D., Mckenzie, T.L., Alcaraz, J.E., Kolody, B., Faucette, N., Hovell, M.F. (1997). The effects of a 2 -year physical education program (SPARK) on physical activity and fitness in elementary school students. Sports, Play and Active Recreation for Kids, American Journal of Public Health, 87(8), 1328-1334

Sallis, J., Bauman, A., \& Pratt, M. (1998). Environmental and policy interventions to promote physical activity. American journal of preventive medicine, 15(4), 379-397. https://doi.org/10.1016/S0749-3797(98)00076-2

Wang, D., Brown, G., \& Liu, Y. (2015). The physical and non-physical factors that influence perceived access to urban parks. Landscape and urban planning, 133, 53-66. https://doi.org/10.1016/j.landurbplan.2014.09.007

Chandrasiri, O., \& Arifwidodo, S. (2017). Inequality in active public park: a case study of Benjakitti Park in Bangkok, Thailand. Procedia engineering, 198, 193-199. https://doi.org/10.1016/j.proeng.2017.07.083 